\title{
Texture and Grain Growth during the Annealing of Ice
}

\author{
C. J. L. WILSON
}

School of Earth Sciences, University of Melbourne, Parkville, Victoria 3052 Australia

(Received April 6, 1981; in final form July 23, 1981)

\begin{abstract}
Changes in microstructure and texture are described in polycrystalline ice compressed at temperatures of -10 and $-1{ }^{\circ} \mathrm{C}$ and annealed for various times at $-1^{\circ} \mathrm{C}$ without a load. The microstructures, obtained under these conditions, were studied by means of polarized light microscopy, both mean and maximum grain sizes were determined. In the colder finer grained samples $\left(-10^{\circ} \mathrm{C}\right)$ the grain size increase during annealing was not as rapid as the coarser hot worked $\left(-1^{\circ}\right)$ samples. Little textural change was observed in the annealed hot worked samples, however the strong preferred orientation of the colder samples was destroyed with annealing. The change in texture corresponded to a decrease in the grain growth rate and the formation of a stable grain structure. Increasing strain and decreasing the deformation temperature both reduce annealing time and the annealed grain size.
\end{abstract}

\section{INTRODUCTION}

Experimentally deformed and naturally occurring ice has been subject to numerous optical studies as the main means of characterizing its texture and microstructure. However, in the glaciological literature the term texture commonly refers to the sizes and shapes of the individual grains and inclusions in a polycrystalline ice aggregate. Whereas the term fabric is used to refer to the distribution of grain orientations particularly the crystallographic axes of individual ice crystals. In this paper the writer proposes to use the terms texture and microstructure in uniformity with most workers in synthetic aggregates, particularly metals, and as used by many structural petrologists (see Vernon, 1968) for metamorphic rocks. In fact many of the products of metamorphism described in ice (see Kingery, 1963) are comparable to grain growth features observed in metals (see Kuon and Jonas, 1973).

Textural studies in lh ice, which has a hexagonal crystal form (Hobbs, 1974), 
have concentrated on the orientation of the crystallographic $c$ axes with only a limited amount of data on the $a$-axis orientation. Non-random textures develop in ice during deformation and common textures, plotted on the lower hemisphere of the stereographic net, range from small circle patterns in uniaxial compression to patterns with one, two, three, or four maxima in simple shear. Associated with these changes in texture are changes in microstructure, with coarse interlocking irregular crystals of multiple maximum fabrics, and finer more equant crystals characteristic of weakly-oriented or single-maximum fabrics (see Budd, 1972). Recrystallization and grain growth not only occur during deformation but also after deformation is completed and the stress (or strain rate) has been removed (Steinemann, 1958).

Deformed ice in nature is usually complicated by the fact that the temperature distribution from the cold top surface to the warm bottom surface in either thin ice sheets or polar ice caps (Gow, 1969; Russell-Head and Budd, 1979) is accompanied by substantial changes in textural, microstructural and other physical properties. It has also been shown by Gow (1969) that there is both a time and temperature dependence for the grain growth of natural ice. Other than the experiments of Steinemann (1958) and Rigsby (1960) the effect of temperature on texture and microstructure has not been tested in the laboratory. Therefore, the purpose of the present study is to describe examples of ice (deformed at -1 and $-10^{\circ} \mathrm{C}$ ) annealed at $-1^{\circ} \mathrm{C}$, which will throw some light on the processes involved in texture formation.

\section{EXPERIMENTAL PROCEDURE}

Deformation techniques The ice samples $(\sim 50 \times 50 \times 60 \mathrm{~mm})$ used in this study (Table I) were deformed in pure shear as described by Wilson and Russell-Head $(1979,1982)$ at temperatures of either $-10^{\circ} \mathrm{C}$ or $-1^{\circ} \mathrm{C}$. During deformation specimens were restricted in one direction and underwent a plane strain deformation. (Here the extension direction is $\mathrm{X}$, the direction of no length change $\mathrm{Y}$, and $\mathrm{Z}$ is the shortening direction). At the end of an experi-

TABLE I

\begin{tabular}{ccccc}
\hline $\begin{array}{c}\text { Experiment } \\
\text { number }\end{array}$ & $\begin{array}{c}\text { true axial } \\
\text { compressive strain } \\
\bar{\varepsilon}\end{array}$ & $\begin{array}{c}\text { rate of } \\
\text { deformation }_{\dot{\varepsilon} \sec ^{-1}}\end{array}$ & $\begin{array}{c}\text { mean grain size } \\
\text { of deformed } \\
\text { sample } \\
d_{0}(\mathrm{~mm})\end{array}$ & $\begin{array}{c}\text { temperature } \\
\text { of deformation } \\
\mathrm{T}^{\circ} \mathrm{C}\end{array}$ \\
\hline $1-9$ & 0.21 & $6 \times 10^{-6}$ & 0.87 & -1 \\
$10-2$ & 0.11 & $3.7 \times 10^{-5}$ & $0 \cdot 67$ & -10 \\
$10-4$ & 0.36 & $3.5 \times 10^{-7}$ & 0.82 & -10 \\
\hline
\end{tabular}


ment the temperature of the enclosing circulating kerosene bath was dropped slowly $\left(-2^{\circ} \mathrm{C} \mathrm{hr}^{-1}\right)$ to $-17^{\circ} \mathrm{C}$ in order to undertake a slow quench. Because of the experimental techniques used, no kinetic information can be obtained before the specimen is unloaded. Under these circumstances it is assumed that all grain nucleation either as subgrains or recrystallized grains has taken place and that limited static recrystallization has occurred after deformation. Deformed specimens were then cut into slabs varying from $3 \mathrm{~mm}$ to $10 \mathrm{~mm}$ thick and annealed in a kerosene bath at $-1 \pm 0.02^{\circ} \mathrm{C}$ for periods of time ranging from 1 day to 39 days. The amount of initial sample available for these annealing studies was limited and sometimes showed variations in finite strain distribution (Wilson and Russell-Head, 1982). This latter feature probably contributes to some of the scatter observed in the grain size variations.

Microstructural and textural examination After annealing specimens were transferred to a cold room at $-10^{\circ} \mathrm{C}$, mounted, sectioned and thinned as outlined by Langway (1958). Quantitative measurements of mean grain diameter, $d_{0}$, using the mean linear intercept method were made along lines parallel to $\mathrm{X}$ and $\mathrm{Z}$, and at a depth of $0.5 \mathrm{~mm}$ from the $\mathrm{XZ}$ surface. Using the same sections the mean of the three largest grain sizes as a function of time (the " $D_{\max }$ method"; Exner, 1972) was determined. While relatively simple, such a technique is limited by the volume increase in grain size, owing to onset of impingement or mutual contact between grains and specimen edge effects. The preferred orientation of the optic $c$ axis of the ice grains was measured on a Rigsby stage (Langway, 1958) and plotted as scatter diagrams on the lower hemisphere of an equal angle stereographic net.

\section{MICROSTRUCTURAL CHANGES AND MECHANISMS}

Deformed material The deformed microstructures in all the ice aggregates tested showed uniform optical characteristics. At $-1^{\circ} \mathrm{C}$ (Figure 1a) the deformed grain size is appreciably larger than the $-10^{\circ} \mathrm{C}$ deformed samples (Figures, 3a, 4a), and in all samples there is a suggestion that grains are elongated in the direction parallel to extension, X. Deformed grains are recognised by the presence of deformation bands (Figure 2a). Smaller strain free grains clearly contrast with the deformed primary grains (Figure $2 b$ ). These smaller grains are strongly delineated and are sometimes dissociated from grain boundaries (Figure 2c). However, some are associated with original grain boundaries (Figure 4a) and occasionally with deformation band boundaries. Using optical techniques, it is often difficult to distinguish between relict grains and recrystallized grains.

These microstructures are comparable to other ice studies described by 


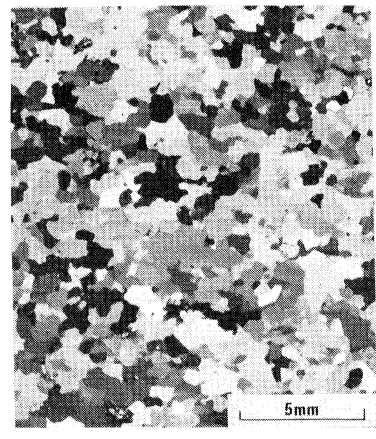

a

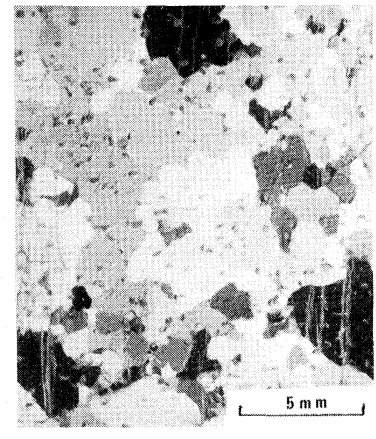

b

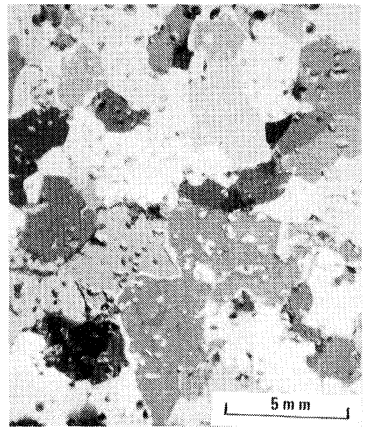

c

FIGURE 1 Microstructures of ice illustrating the progress of annealing at $-1^{\circ} \mathrm{C}$ in sample 1-9. (a) at completion of deformation. (b) annealed for 3 days. (the vertical lines are cracks produced during thin section preparation). (c) annealed for 8 days.

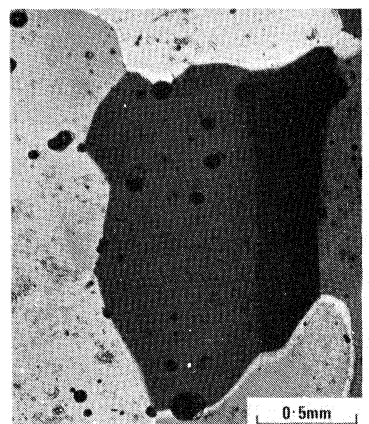

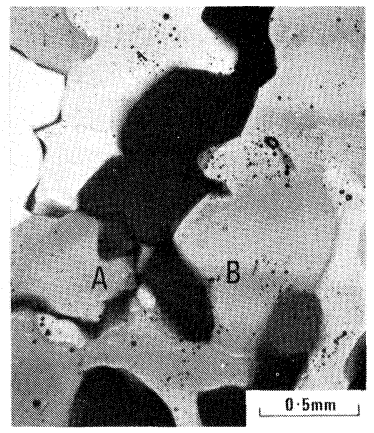

b

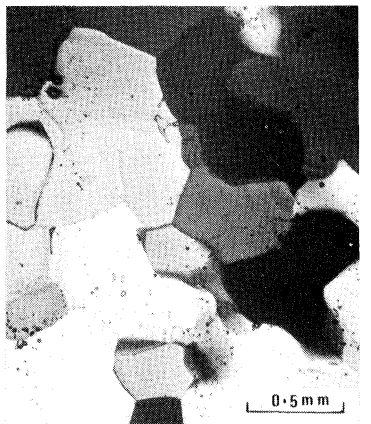

C

FIGURE 2 Micrographs showing microstructure associated with deformed ice grains in sample 1-9. (a) deformation band in relict primary grain. (b) small recrystallized grains on margin of deformed grain at A and small misorientation across a deformation band boundary at B. (c) recrystallized grain aggregate.

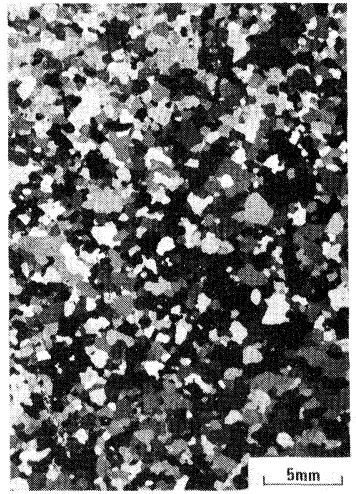

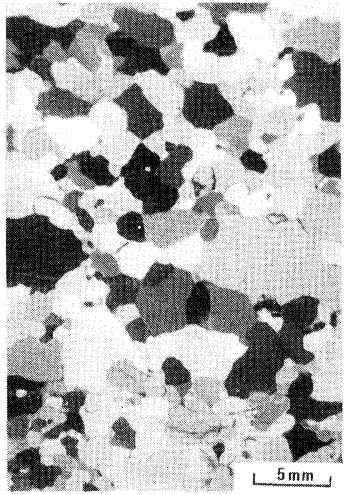

b

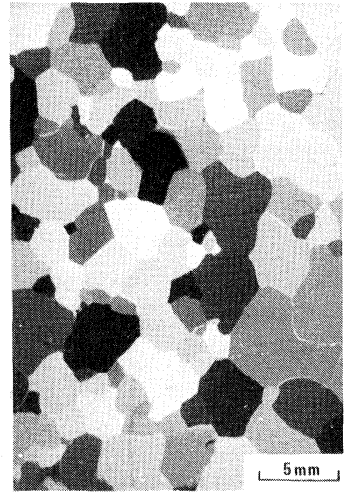

C

FIGURE 3 Microstructure associated with ice sample 10-2. (a) at completion of deformation. (b) annealed at $-1^{\circ} \mathrm{C}$ for 3 days. (c) annealed at $-1^{\circ} \mathrm{C}$ for 8 days. 
Steinemann (1954, 1958), Rigsby (1960), Gold (1963), and Wakahama (1964) where deformation is associated with intracrystalline slip predominantly on the basal plane, (0001). The slip is accompanied by dynamic recovery and recrystallization processes with nucleation preferentially occurring at grain boundaries (Rigsby 1960). When deformation is stopped, some nuclei continue to grow (Steinemann, 1958; Wakahama, 1964).

Annealed material The annealing of the ice deformed at $-1^{\circ} \mathrm{C}$ produced irregular increases in grain size and grain shape (Figures $1 \mathrm{~b}, 1 \mathrm{c}$ ), and features such as deformation bands were absent. Figure 1b shows that during the initial period of annealing an obvious duplex grain structure was developed, which persisted with time (Figure 1c). All grains are bounded by smoothly curved grain-boundaries, and the shape of the boundaries is consistent with migration towards their centres of curvature.

Annealing the colder $-10^{\circ} \mathrm{C}$ ice resulted in a grain-structure that consisted of polygonal, equant grains with smoothly curved or straight interfaces (Figures 3c, 4c). Marked grain size variations (Figure 3b) were observed during the initial stages of annealing. This became less once the curvature (Figure 4b) of the migrating grain boundary decreased and the shape of the grains became polygonal with dihedral angles of $120^{\circ}$.

\section{GRAIN SIZE VARIATION}

The annealed mean grain diameter, $d_{0}(\mathrm{~mm})$, versus time is shown in Figure 5a. The initial rate of grain diameter increase is the same in experiments 1-9 and $10-4$, but has a greater rate of increase in the less deformed $-10^{\circ} \mathrm{C}$ sample (experiment 10-2). This rate of grain growth decreases after 4, 20 and 40 days in experiments 10-2, 10-4 and 1-9 respectively. This growth cessation and development of a steady state grain size is first attained in the coldest and least deformed specimen. Whereas the sample (experiment 1-9) deformed at a higher temperature, but not with the greatest strain, continued to undergo grain growth for the longest time. Grain diameter also varies with direction of measurement being greater parallel to the extension direction $(\mathrm{X})$ and smaller parallel to the direction of shortening $(\mathrm{Z})$. This trend is persistent through all the annealed samples of the $-1^{\circ} \mathrm{C}$ experiment, but is less obvious in the longer annealed samples of the $-10^{\circ} \mathrm{C}$ experiments. The greatest difference in grain size with direction of measurement observed in experiment 1-9 is shown by the error bar in the 42 day anneal (Figure 5a).

The rate of increase in maximum grain diameter $\left(D_{\max }\right)$ for the coldest and least deformed sample (10-2) was at the same rate and had approximately the same magnitude of increase as $d_{0}$ (Figure $5 b$ ). With increased strain (experiment 10-4) $D_{\max }$ was slightly greater than $d_{0}$. Whereas in experiment 

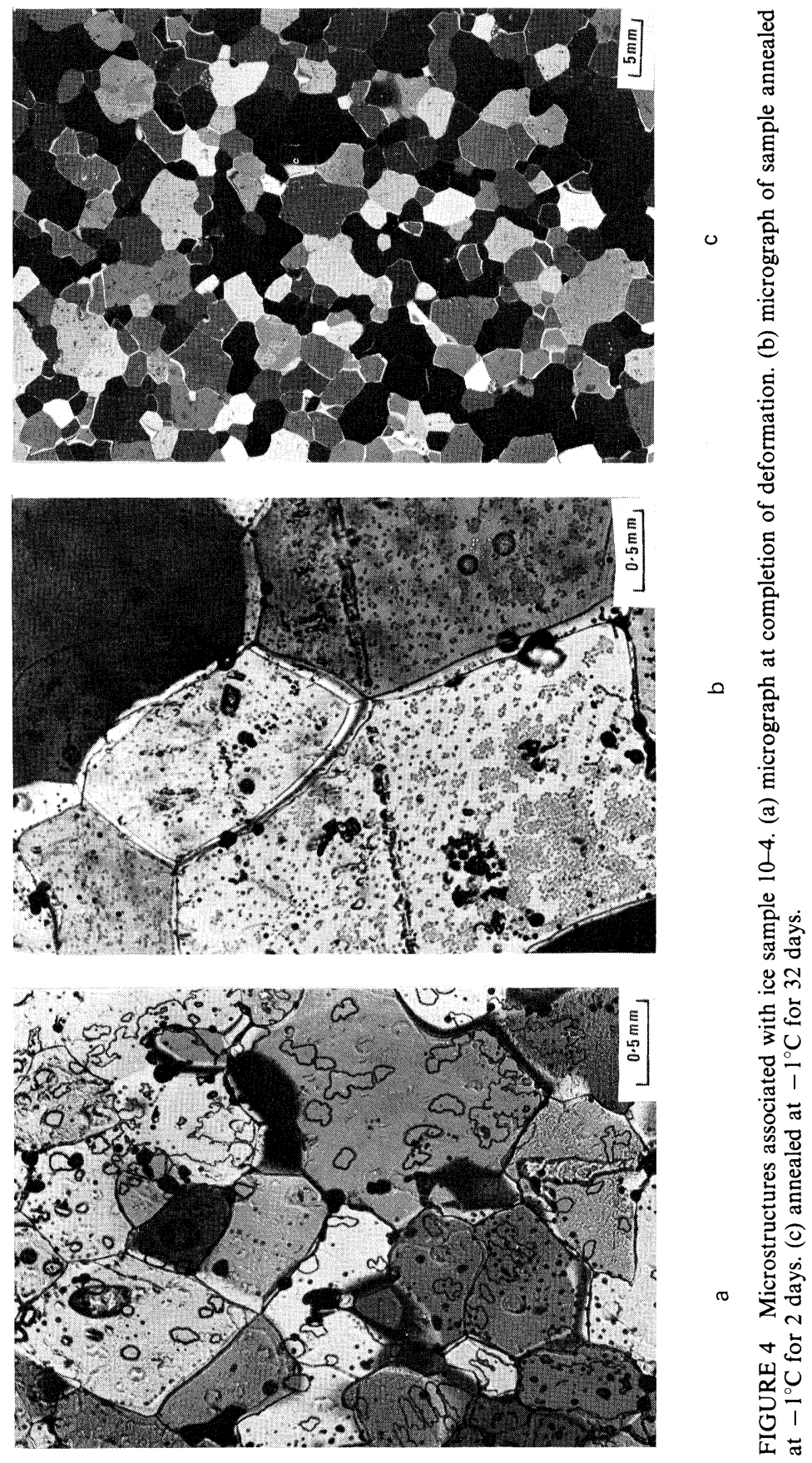
Time(days)

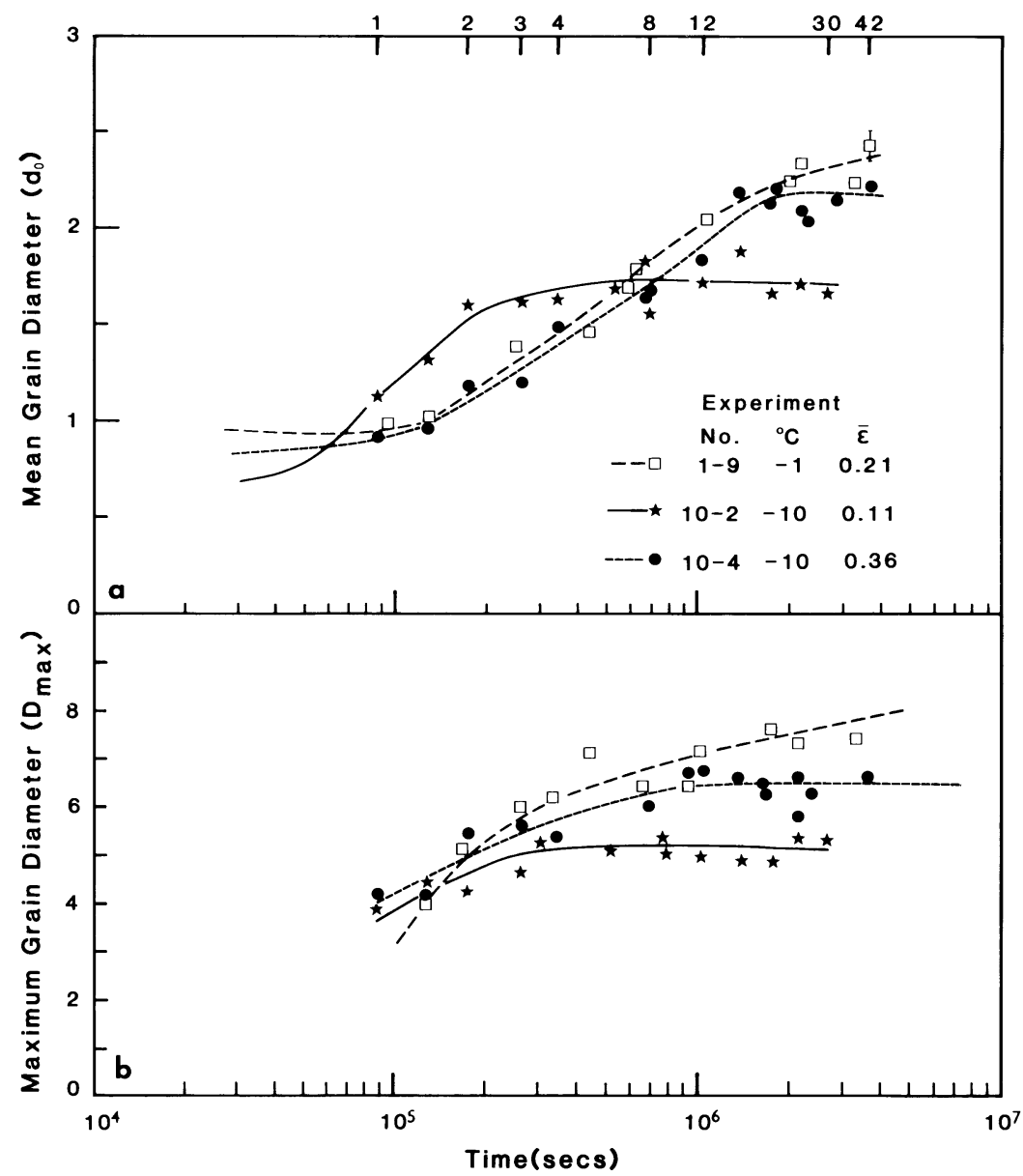

FIGURE 5 Isothermal annealing curves for the differently deformed samples of polycrystalline ice. (a) mean grain diameter $(\mathrm{mm})$ versus $\log$ time. (b) maximum grain diameter $(\mathrm{mm})$ versus $\log$ time.

1-9 where the sample has been deformed at a higher temperature, the $D_{\max }$ growth rate was apparently greater than $d_{0}$.

An interesting consequence of the growth rates decreasing so rapidly with time in the $-10^{\circ} \mathrm{C}$ samples, is that the numerous nuclei present in the finegrained deformed ice will account for a disproportionately small fraction of grains in the annealed volume. Grains are therefore effectively impinged early in annealing even though a certain amount of time dependent grain growth occurs. Whereas the initial coarse grain size of the $-1{ }^{\circ} \mathrm{C}$ sample and smaller 
number of nuclei per unit volume has lead to a relatively large annealed grain size. Comparable observations have also been made in metals (English and Backofen, 1964) where large grains established in the deformation exert control on the final grain size.

Since the driving force for grain boundary migration in the annealing experiments decreases as the grain size is increased, if all nuclei have impinged, these experiments provide a study of grain boundary migration over a range of driving forces. The observed annealing kinetics indicate that there are two steady-state regions of grain growth, an interval of rapid growth versus an interval of little grain size increase. These two regions are presumably associated with different activation energies and/or kinetics. The two steady state regions of grain growth may be interpreted in terms of (1) high velocity driving force and (2) a region where grain boundary impingement has resulted in a cessation of grain growth.

\section{TEXTURAL CHANGES}

The pole figures showing the pre-annealed orientations and annealed $c$-axis orientations are shown in Figures 6 to 8. It is well established (Budd, 1972; Kamb, 1972) that during the plastic deformation of polycrystalline ice, crystals rotate through intracrystalline slip and develop distinct "end orientations" (Lister, 1978). The strength of the "end orientation" is a measure of the strain (Wilson and Russell-Head, 1982). The "end orientation" $c$-axis pattern in ice deformed in pure shear is a double maximum lying in the 25 to $50^{\circ}$ smallcircle girdles about the shortening axis $\mathrm{Z}$. Such a preferred orientation pattern is clearly developed in ice where compressive shortenings exceed 0.2 (cf. Table 1).

Evidence of the "end orientation" texture can be seen in all the deformed
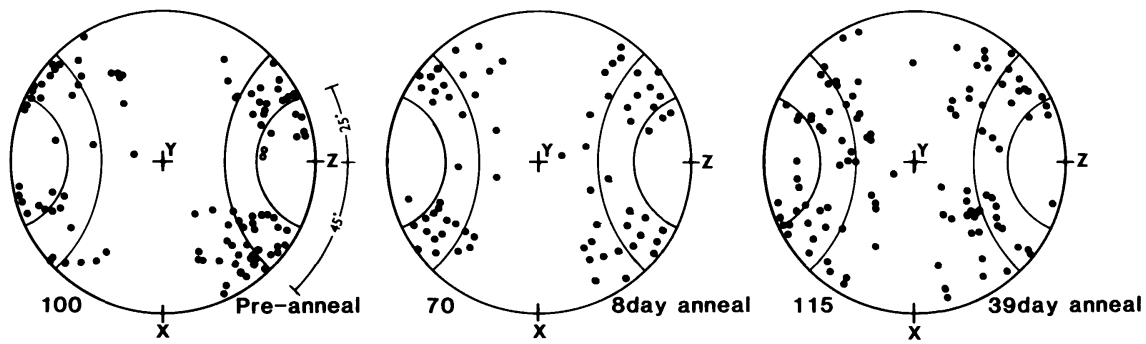

FIGURE 6 Patterns of $c$-axis orientations observed in ice 1-9. All measurements were recorded from XZ sections. The superimposed small circles are at $25^{\circ}$ and $45^{\circ}$ to the shortening axis $Z$. The number of $c$-axes is shown on the bottom left of each equal-angle projection and the number of days any sample was annealed is shown on the bottom right of the projection. 

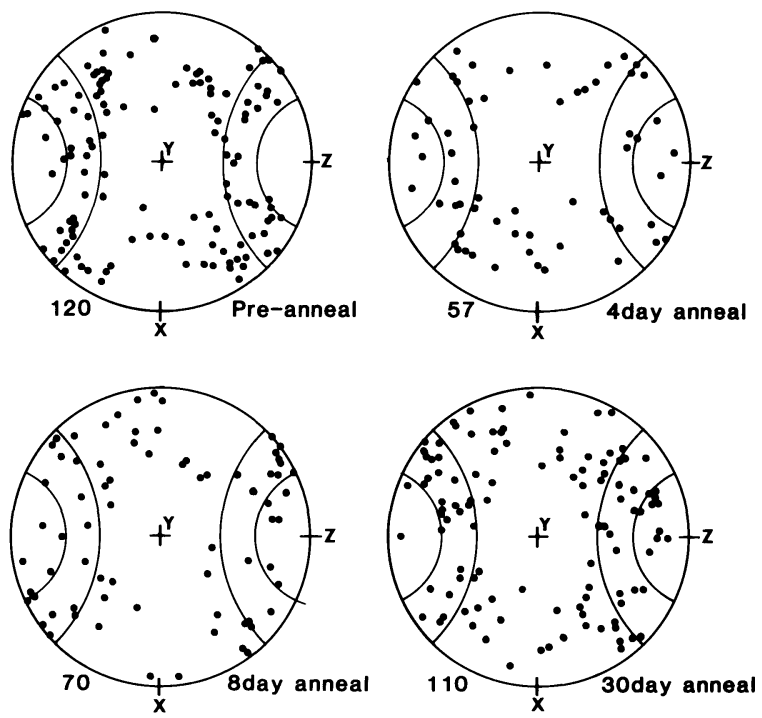

FIGURE 7 Patterns of $c$-axis orientations observed in ice 10-2.
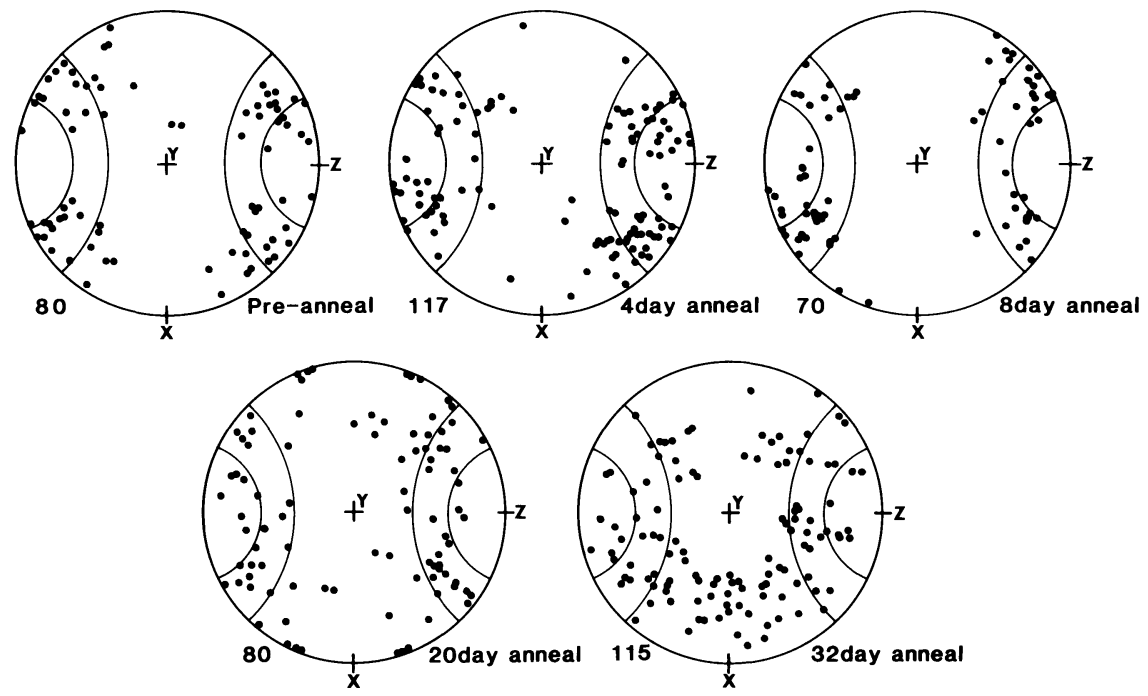

FIGURE 8 Patterns of $c$-axis orientations observed in ice 10-4. 
samples prior to annealing. In 1-9 (Figure 6) and 10-4 (Figure 8) there are distinct concentrations of $c$-axes lying between and adjacent to the $25^{\circ}$ and $45^{\circ}$ small circles centred on the shortening direction. A small proportion of the grains fall within 45 and $60^{\circ}$ cones, with very few lying at a high angle to the shortening direction $\mathrm{Z}$. In 10-2 (Figure 7) a sample that has undergone less strain, the "end orientation" texture is not as clearly developed. However there is still a high proportion of grains with $c$-axes lying between the 25 and $45^{\circ}$ small circle. There is also a noticable decrease of $c$-axes near the $\mathrm{Y}$ and $\mathrm{Z}$ axes.

Annealing of ice deformed at $-1{ }^{\circ} \mathrm{C}$ (Wilson, 1981; Wilson and RussellHead, 1982) significantly decreases the number of grains but the texture is not altered with prolonged heating. An example of this can be seen in Figure 6 where textures were recorded from samples after 8 and 39 days. These textures are comparable to those observed in the deformed material prior to annealing.

The initial annealing of the $-10^{\circ} \mathrm{C}$ samples did not produce marked departures in texture from their pre-annealed starting material. This can be seen in the 4 and 8 day anneals (Figures 7 and 8). With prolonged heating, the $-10^{\circ} \mathrm{C}$ ice that had a well defined pre-anneal texture, shows quite marked textural changes, with the loss of the pre-existing pattern and the development of variably oriented grains (e.g. the 32 day anneal in Figure 8). The transition between these two types of patterns is seen in the 20 day anneal (Figure 8), where the basic "end orientation" of the deformed sample exists with a number of variably oriented grains. These textural changes coincide with the change in growth rate (Figure 5a) during annealing. Where the pre-annealed texture is not well defined (experiment 10-2), the textural changes with annealing are less obvious (Figure 7).

Therefore in the $-10^{\circ} \mathrm{C}$ ice, where the lower temperature appears to allow the development of many more nuclei, annealing is damaging to the maintenance of a good preferred orientation. This probably arises because there is insufficient time during the annealing for the grain boundaries to become stable. The initial period of grain growth would involve the migration of unstable boundaries thus preserving the pre-anneal texture. In the $-1^{\circ} \mathrm{C}$ samples where the ice has been effectively strongly hot worked at higher temperatures, the migration of existing boundaries predominates, as the source for the annealed nuclei, thus preserving the "end orientation" of the pre-annealed samples.

\section{DISCUSSION}

Annealing is of utmost importance and is widely recognised in most naturally occuring ice aggregates (Rigsby, 1968). In comparison to metallurgical studies 
there are few research papers that have been devoted to the subjects of annealing, grain boundary migration and grain growth in ice. The results presented here indicate that there is a strong comparison between ice and the phenomenon observed during classical isothermal annealing (Margolin, 1966). It can be seen that in both ice and metals (Barraclough and Sellars, 1979) the shape of the isothermal annealing curves depend upon the strain, strain rate and temperature of the prior deformation.

In experiment 1-9 the close similarity between (1) the shape of deformed and annealed grains and (2) the texture, provide reason to believe that nuclei for the growth of grains came from the deformed state. Since lattice curvatures are necessary in the nucleation of recrystallization e.g. the vicinity of grain boundaries and deformation bands (Hutchinson, 1974), it may be expected that the annealed texture components will be close to the deformation texture as proposed by $\mathrm{Hu}$ (1969). As pointed out by Higgins (1974) any grain with a boundary of particularly high mobility will maintain this position throughout annealing, and hence may not change the texture. With the lower temperature deformations there was a marked limit to the grain boundary migration velocity during annealing and a distinct change in grain shape. This could reflect the nature of the grain boundary misorientations in the deformed state (Doherty and Cahn, 1972). Similarly, the change in texture may reflect the competition between grain boundary migration and recrystallization processes as proposed by Dillamore and Fletcher (1966). Alternatively the textural change could be attributed to the growth of grains possessing the widest orientation differences in colonies of different grain size distributions (Higgins, 1974). Unfortunately the precise nature of the recrystallization and the nature of the grain boundaries in ice is still a subject to be investigated and could not be verified in this optical study.

These ice observations are also analogous to those made during the annealing of quartz by Green, Griggs and Christie (1970) where new patterns of preferred orientations, markedly different from those in the deformed material, were produced in samples which did not exhibit grain growth during deformation. Whereas, high temperature deformation of quartz, under hot working conditions, resulted in a recrystallized aggregate that had undergone grain growth. Annealing of this aggregate strengthened the c-axis pattern without any change to the orientation.

\section{CONCLUSIONS}

The combined results of microstructural and textural studies indicate that pronounced differences arise from annealing ice deformed at $-1^{\circ} \mathrm{C}$ and $-10^{\circ} \mathrm{C}$. The following conclusions are drawn: 
1) The time required for annealing to attain a stable grain size decreased with increasing strain and/or temperature.

2) The time to attain the stable annealed size is shorter for smaller grain sizes.

3) The annealed grain size is directly dependent on the original grain size.

4) A relationship between the microstructure of the deformed ice and the orientation of annealed nuclei is strongly suggested by the preservation of pre-annealed textures.

During annealing a new texture dependent on the previous one is being formed suggesting that for such a situation oriented growth as described by Hu (1969) may be operating.

5) The destruction of pre-anneal textures only occurs with prolonged heating of ice deformed under colder conditions. The change in texture from a strong $c$-axis pattern of preferred orientation to a more variably oriented pattern also corresponds to a change in growth rate.

6) In polycrystalline ice deformed at temperatures close to its melting point annealing produces insignificant textural changes.

\section{Acknowledgements}

This work was financially supported by the Australian Research Grants Committee. D. RussellHead, T. Dukovcic and S. Marshallsea are thanked for their technical help at different stages of this work. W. F. Budd is thanked for his comments on the manuscript.

\section{References}

Barraclough, D. R. and Sellars, C. M. Metal Sci. 13, 257 (1979).

Budd, W. F. Zeitschr $f$ Gletscherk $u$ Glazialgeol. 8, 1 (1972).

Dillamore, I. L. and Fletcher, S. F. H. In: Margolin, H. (ed.) Recrystallization, Grain Growth and Textures. A.S.M., Metals Park, Ohio, 448 (1966).

Doherty, R. D. and Cahn, R. W. J. Less-Common Metals 28, 279 (1972).

English, A. T. and Backofen, W. A. Trans. TMS-AIME 230, 396 (1964).

Exner, H. E. Inter. Met. Review 17, 25 (1972).

Glover, G. and Sellars, C. M. Met. Trans. 3, 2271 (1972).

Gold, L. W. In: Kingery, W. D. (ed.) Ice and Snow, properties, processes and applications. M.I.T. Press, Cambridge 8 (1963).

Gow, A. J. J. Glaciol. 8, 241 (1969).

Green, H. W., Griggs, D. T. and Christie, J. M. In: Paulitsch, P. (ed.) Experimental and Natural Rock Deformation. Springer-Verlag, Berlin 272 (1970).

Higgins, G. T. Metal Sci. 8, 143 (1974).

Hobbs, H. A., Cutcliffe, J. L. and Kingery, W. D. In: Kingery, W. D. (ed.) Ice and Snow, properties, processes and applications. M.I.T. Press, Cambridge 311 (1963).

Hobbs, P. V. Ice Physics. Clarendon Press, Oxford (1974).

$\mathrm{Hu}$, H. In: Grewen, J. and Wasserman, G. (eds.) Textures in Research and Practice, (SpringerVerlag, Berlin, 200, 1969).

Hutchinson, W. B. Metal Sci. 8, 185 (1974). 
Kamb, B. W. Am. Geophys. Union Monog. 16, 211 (1972).

Kingery, W. D. (ed.) Ice and Snow, properties, processes and applications. M.I.T. Press, Cambridge. (1963).

Kuon, L. G. and Jonas, J. J. In; Whalley, E., Jones, S. J. and Gold, L. W. (eds.) Physics and Chemistry of Ice. Royal Society Canada, Ottawa, 1973 370, (1973).

Langway, C. C. Ice Fabrics and the Universal Stage. SPIRE Tech. Rept. 52, (1958).

Lister, G. S. In: Gottstein, G. and Lücke, K. (eds.) Textures of Materials. (Springer-Verlag, Berlin 2, 199 (1978).

Margolin, H. (ed.) Recrystallization, Grain Growth and Textures. A.S.M., Metals Park, Ohio (1966).

Rigsby, G. P. J. Glaciol. 3, 509 (1960).

Rigsby, G. P. J. Glaciol. 7, 233 (1968).

Russell-Head, D. S. and Budd, W. F. J. Glaciol. 24, 117 (1979).

Steinemann, S. J. Glaciol. 3, 509 (1954).

Steinemann, S. Beitr. Geol. Schweiz. Hydrologie 10, 7 (1958).

Vernon, R. H. J. Petrol. 9, 1 (1968).

Wakahama, G. Low Temp. Sci. 22, 1 (1964).

Wilson, C. J. L. Tectonophysics 78, 139 (1981).

Wilson, C. J. L. and Russell-Head, D. S. Nature 279, 49 (1979).

Wilson, C. J. L. and Russell-Head, D. S. J. Glaciol. 28, in press (1982). 